\title{
Aa. Vv., «Feritas», «humanitas» $e$ «divinitas» come aspetti del vivere nel Rinascimento, Atti del XXII Convegno Internazionale, a cura di Luisa Secchi Tarugi
}

Filippo Fassina

\section{(2) OpenEdition}

\section{Journals}

Edizione digitale

URL: https://journals.openedition.org/studifrancesi/2121

DOI: $10.4000 /$ studifrancesi.2121

ISSN: 2421-5856

\section{Editore}

Rosenberg \& Sellier

\section{Edizione cartacea}

Data di pubblicazione: 1 avril 2014

Paginazione: 134-135

ISSN: 0039-2944

\section{Notizia bibliografica digitale}

Filippo Fassina, «Aa. Vv., «Feritas», «humanitas» e «divinitas» come aspetti del vivere nel Rinascimento, Atti del XXII Convegno Internazionale, a cura di Luisa Secchi Tarugi», Studi Francesi [Online], 172 (LVIII | I) | 2014, online dal 01 avril 2014, consultato il 22 septembre 2021. URL: http://journals.openedition.org/ studifrancesi/2121; DOI: https://doi.org/10.4000/studifrancesi.2121

\section{Questo documento è stato generato automaticamente il 22 septembre 2021.}

\section{c) (1) (9)}

Studi Francesi è distribuita con Licenza Creative Commons Attribuzione - Non commerciale - Non opere derivate 4.0 Internazionale. 


\section{Aa. Vv., «Feritas», «humanitas»e «divinitas» come aspetti del vivere nel Rinascimento, Atti del XXII Convegno Internazionale, a cura di Luisa Secchi Tarugi}

Filippo Fassina

\section{NOTIZIA}

AA. VV., «Feritas», «humanitas» e «divinitas» come aspetti del vivere nel Rinascimento, «Atti del XXII Convegno Internazionale» (Chianciano Terme - Pienza, 19-22 luglio 2010), a cura di Luisa SECCHI TARUGI, Firenze, Franco Cesati Editore, 2012 ("Quaderni della Rassegna», 77), pp. 707.

1 Questa ampia e variegata miscellanea ha come filo conduttore il dibattito tipicamente rinascimentale sulle varie tipologie del vivere umano, che possono andare dalla ferinità che accomuna gli uomini alle bestie, fino all'elevazione morale che rende l'essere umano simile a una divinità. Questa varietas trova riscontro in una pluralità di discipline: nella letteratura, nell'arte, nella filosofia, nella musica, nel teatro e nella teologia. Allo stesso modo, questi contributi offrono un panorama estremamente ricco e variegato di un aspetto culturale e sociale di grande rilevanza nel Cinquecento. Anche dal punto di vista geografico, i testi qui inseriti spaziano dall'Italia alla Francia, dalla Spagna alla Germania, senza trascurare i testi classici e prendendo in considerazione una vastissima tipologia di discipline e di generi letterari. In questa sede è opportuno segnalare di seguito i contributi che interessano la Letteratura francese.

2 François RoUDAUT, «Feritas», «humanitas», «divinitas» e il tempo nei «Sonnets por Hélène» di Ronsard (pp. 173-186): vengono analizzati i concetti alla luce dell'interpretazione che ne 
dà Ronsard nel contesto amoroso dei suoi Sonnets. La feritas assume i connotati dello sconvolgimento dell'essere provocato dall'amore e viene costruito un vero e proprio percorso di innalzamento che porta l'uomo a essere pienamente attore della propria vita riscattandosi dalla bestialità e tendendo verso l'eternità.

Myriam JACQUEMIER, «Feritas», "humanitas» et «divinitas» comme aspects de 'vivre' à la Renaissance dans «Microcosme» de Maurice Scève (pp. 197-214): nel testo di Scève si intrecciano numerose tematiche legate a vita, amore e morte. E nella vita dell'uomo la dignità sta proprio nel riuscire a sintetizzare humanitas, feritas e divinitas elaborando una vera e propria art de vivre che renda l'essere umano allo stesso tempo materiale e spirituale. In questo, un ruolo fondamentale ha l'amore che allo stesso tempo rende l'uomo fragile, ma gli permette di riflettere su se stesso e sulla sua condizione.

Denis BJAï, Le «bon Troien» et le «fier Gean»: enjeux éthiques et politiques du duel entre Francus et Phovère dans "La Franciade» de Ronsard (pp. 283-292): vengono rintracciati i caratteri dell'umanità e della bestialità all'interno del celebre episodio del duello fra Francus e Phovère. Viene sottolineato il sottile gioco delle parti che si crea nella caratterizzazione dei personaggi, in base alla quale anche Francus, per sconfiggere l'avversario deve assumerne i tratti ferini e rinunciare per un momento alla sua connotazione puramente eroica.

5 Étienne wolfF, L'adage 3001 d'Érasme: la critique de la guerre à la lumière del 'Antiquité (pp. 305-314): la tematica principale di questo adage, che viene analizzato sia dal punto di vista concettuale, sia da quello stilistico e lessicale, è fondamentalmente il rapporto fra l'uomo e la guerra. Il fine ultimo del componimento è proprio quello per cui l'uomo realizza pienamente la sua humanitas soltanto nella pace, mentre la guerra non porta nessun giovamento e turba l'uomo sia dal punto di vista fisico, sia morale e, pertanto, è da combattere in tutti i modi possibili.

6 Yvonne BELLENGER, Vertu et cruauté: «feritas», «humanitas» et «divinitas» dans les «Essais» de Montaigne (pp. 359-367): vengono esaminati i concetti alla base di questi studi secondo l'accezione che Montaigne dà nella sua opera. Il termine feritas, indica fondamentalmente la crudeltà e la condizione selvaggia dell'uomo, che culmina nel cannibalismo. Tuttavia, il principio secondo il quale il diverso non è necessariamente peggiore o inferiore permette a Montaigne di vedere sotto una nuova luce anche la feritas, intesa come bassezza dell'uomo. Allo stesso modo, anche la virtù e la religione vengono riviste secondo un modello non sempre positivo, in quanto frutto di uno sforzo che spesso va contro la natura umana.

Bruno LAVILLATTE, Vivre et penser les monstres à la Renaissance: une verité troublante (pp. 461-476): l'A. offre un'interessante panoramica sul concetto di mostruorità intesa non solo in senso fisico, ma anche e soprattutto secondo il significato di 'strano' o 'inquietante'. Citando come esempi i testi di Rabelais, Montaigne e Agrippa d'Aubigné, viene descritto un procedimento di decostruzione di ciò che viene ritenuto strano e che continuerà per tutto il Cinquecento, gettando le basi per quel processo di razionalizzazione il quale culminerà con l'opera di Descartes.

Alba CECCARELLI PELLEGRINo, Il poeta e l'architetto «à l'école des bêtes» (pp. 477-502): vengono analizzate e comparate due opere, i Traités d'Architecture di Philippe de l'Orme (1567) e il poema di Ronsard La Fourmy (1554). In entrambi i testi l'uomo è paragonato a un animale (l'architetto a un serpente e il poeta a una formica) creando così una 
simbologia sottile che si configura come una vera e propria riflessione teorica sull'arte e sulla poesia.

Daniela MAURI, «Humanitas» $e$ "divinitas» nell'«Idée de la république» di Béroalde de Verville (pp. 585-596): viene analizzato dettagliatamente il testo di Béroalde de Verville, un poema in alessandrini pubblicato nel 1584 che si inserisce nel genere letterario dell'utopia, in quanto descrive la realtà come una piramide al cui vertice è situato Dio $\mathrm{e}$ alla cui base si trova il popolo, inteso come insieme dei rapporti umani di ogni genere. La sintesi di questa visione è uno stretto rapporto tra divinitas e humanitas, che è alla base della natura stessa dell'uomo e, di conseguenza, diventa anche il motore dell'ispirazione poetica.

Bruno MÉNIEL, Colère humaine, colère divine: Moïse à la Renaissance (pp. 609-622): l'A. analizza la figura di Mosè come viene percepita nella letteratura classica e moderna. interessante notare come i poeti protestanti francesi utilizzino Mosè come simbolo dell'uomo che domina la natura e che diventa mediatore tra i mortali e Dio e, attraverso la sua figura, si pongono il problema teologico della violenza compiuta in nome di Dio. 